ЗАХАРКИН Роман Александрович - кандидат социологических наук, доцент департамента коммуникаций и медиа Школы искусств и гуманитарных наук Дальневосточного федерального университета (690922, Россия, Приморский край, г. Владивосток, о. Русский, n. Аякс, 10; rom_zah@таil. ru,zakharkin.ra@dvfu.ru)

АРГЫЛОВ Никита Антонович - кандидат политических наук, научный сотрудник департамента коммуникаций и медиа Школы искусств и гуманитарных наук Дальневосточного федерального университета (690922, Россия, Приморский край, г. Владивосток, о. Русский, n. Аякс, 10; argylov.na@ dvfu.ru)

\title{
ИНФЛЮЕНСЕРЫ КАК МЕДИАЗНАЧИМЫЕ ДРУГИЕ: СОВРЕМЕННЫЕ ТРЕНДЫ ВТОРИЧНОЙ СОЦИАЛИЗАЦИИ
}

\begin{abstract}
Аннотация. Статья посвящена изучению в социологическом ключе такого актуального явления современного общества, как инфлюенсер. С использованием иностранных источников дается определение понятия, выделяются общие черты, характерные для инфлюенсеров. Авторы отмечают тенденцию в отечественных источниках отождествлять инфлюенсера и лидера мнений, а также относить инфлюенсеров к сфере продвижения товаров и услуг. В качестве критики такого подхода рассматривается теория «двухступенчатого потока информации» П. Лазарсфельда. Авторы предлагают использовать более корректный термин - «медиазначимый другой», раскрывают суть этого феномена и его взаимосвязь с явлением «инфлюенсер", а также ставят под сомнение тезис, что инфлюенсеры могут оказывать воздействие только в сфере продаж. В результате проведенного социологического исследования проверяется и уточняется гипотеза, что инфлюенсеры могут оказывать влияние в областях, не связанных с продажами. Социализирующее воздействие медиазначимых других распространяется на различные области общественной жизни, и такое воздействие только усиливается.
\end{abstract}

Ключевые слова: инфлюенсер, значимый другой, медиазначимый другой, лидер мнения, П. Лазарсфельд, коронавирус, COVID-19

$\mathrm{C}$ овременное общество определяется как информационное. Одной из особенностей такого общества считается определяющая роль в нем информации в целом и медиа в частности. Медиа оказывают огромное влияние на все сферы общества, персонифицируясь в медийных личностях, которых в последнее время обозначают термином «инфлюенсер» (от английского to influence оказывать влияние, влиять). Необходимо отметить, что в академической среде еще окончательно не институционализировалось определение этого явления, может быть, потому, что феномен еще развивается, видоизменяется и охватывает новые уровни общественных отношений.

Так, предложенное Катаржиной Гарвол определение состоит в характеристике инфлюенсеров как людей, которые ведут блог/видеоблог, имеют учетную запись в Instagram, YouТube или какой-либо другой социальной сети и способны влиять на группу из не менее чем сотни людей. Своими постами в социальных сетях инфлюенсеры не только воздействуют на решения своих подписчиков, но и выстраивают с ними отношения, так что фолловеры, как еще называют последователей, отождествляют себя с теми, кто оказывает на них влияние [Garwol 2020: 274].

Международный коллектив авторов статьи «Инфлюенсеры и COVID19: обзор ключевых проблем в прессе Австралии, Китая, Японии и Кореи» характеризует инфлюенсеров следующим образом в соответствии с распространенными в каждой из стран особенностями. В Австралии это наиболее 
часто используемое и универсальное обозначение для интернет-знаменитостей, представителей творческой среды и так называемых микрознаменитостей социальных платформ - ютуберов, инстаграммеров и тому подобных. Аналогично, для Японии термин インフルエンサー (influensā) является наиболее точной и прямой транслитерацией английского influencer; это понятие ориентировано на известных пользователей социальных сетей и не зависит от платформы. Для Кореи 인플루언서 также является частью повседневной речи для обозначения соответствующих пользователей социальных сетей, плюс существуют одинаково популярные альтернативы, такие как 콘텐츠 크리에이터 (создатели контента) и 파워 블로거 (влиятельный блогер). В Китае 网红红 переводится как «золото Интернета» и является самым популярным универсальным выражением для «интернет-знаменитости», «микрознаменитости» и «влиятельной онлайн-персоны» [Abidin et al. 2021: 119].

Еще одно мнение заключается в том, что, в отличие от традиционных знаменитостей, которые получили общественное признание благодаря своему профессиональному таланту, влиятельные люди в социальных сетях (инфлюенсеры) достигли известности, успешно позиционируя себя в качестве экспертов на платформах социальных сетей. Инфлюенсеры привлекают миллионы подписчиков, делясь контентом из их повседневной жизни на таких платформах, как Instagram и YouTube, и развиваясь вокруг одной конкретной области интересов. Авторы данной концепции подчеркивают, что инфлюенсеры начали строить свою карьеру именно в Интернете и раньше были неизвестны широкой публике, в отличие от «традиционных» знаменитостей, которые хотя и нашли свой путь в социальных сетях, но прежде получили известность вне онлайн-пространства [Schouten, Janssen, Verspaget 2019: 2].

Эту же особенность в определении инфлюенсеров подчеркивают испанские исследователи. Инфлюенсеры - это ранее не известные люди, которые сами становятся знаменитостями, привлекая большие онлайн-сообщества подписчиков, заинтересованных в темах, которые они затрагивают. К числу инфлюенсеров исследователи относят блогеров из различных социальных сетей, чей влиятельный статус основан на признании их власти над умами членов онлайн-сообществ, объединенных общими интересами. Фолловеры следят за влиятельными лицами в социальных сетях по различным причинам: от желания подражать образу жизни конкретного блогера, идти в ногу с последними тенденциями до стремления быть членом сообщества, с которым они идентифицируют себя [Monge Benito, Elorriaga Illera, Olabarri Fernández 2020: 152].

Конечно, мы привели не все определения и высказывания зарубежных авторов относительно сущности феномена «инфлюенсер», но, обобщая приведенные мнения и мнения других источников, не упомянутых в статье, можно сделать определенные выводы.

Прежде всего, необходимо отметить, что термин «инфлюенсер» относится к области новых медиа, и в первую очередь социальных сетей, причем прежде всего упоминаются Instagram и YouTube.

Второе, что акцентируется авторами, это отделение инфлюенсеров от селебрити (личностей, получивших известность вне социальных сетей, пришедших в них уже с определенным числом поклонников). Особо уточняется, что инфлюенсеры - это обычные люди, которые получили известность уже в рамках новых медиа, где обрели своих фолловеров. На основе изученного материала мы можем отметить, что селебрити также можно относить к инфлюенсерам, однако порог трансформации в это явление у селебрити намного ниже, т.к. они уже известны до появления в социальных сетях.

Третье - отмечается достаточно тесная связь между инфлюенсером и его 
подписчиками, т.к. у фолловеров появляется желание быть ассоциированным с инфлюенсером, быть частью сообщества, информационного community, которое он создал. Через такую связь и определенную власть, которую имеет инфлюенсер над своим сообществом, состоящим из фолловеров, он может оказывать на них воздействие, т.е. влиять на их взгляды, привычки, поведение, особенности потребления и т.д.

В российском научном сегменте, изучающем инфлюенсеров, в целом дают такие же характеристики этому феномену, но есть нюанс, который прослеживается в работах именно отечественных исследователей. Типичным является отождествление понятий «инфлюенсер» и «лидер мнений»: «как правило, это поколение склонно доверять информации из сети, а именно лидерам мнений (инфлюенсерам)» [Куприянова 2019: 23], «инфлюенсеры могут одновременно транслировать контент как на группы с узкими интересами, повышая эффективность попадания в целевую группу и ее проблемы, так и в широкие группы... Поэтому маркетинговые кампании с лидерами мнений распространяются и развиваются во всех соцсетях, а большинство брендов вообще используют кросс-канальный подход к своим активностям с блогерами» [Никитина 2018: 510]. «Именно "инфлюенсеры” составляют из себя сегмент “макросреды" социальных сетей. Инфлюенсеры в социальных сетях (от английского influence - “влиять”) - это люди, к мнению которых прислушивается определенная интернет-аудитория... Зачастую лидеры мнений создают на своих страницах контент в определенной тематике (мода, путешествия, еда, психология, политика, спорт, дети, образование, кино, журналистика и т.д.) или же на свободную тематику (личный блог, где собраны мысли, мнения и жизненный опыт конкретного человека)» [Вицелярова, Опря, Белякно 2020: 115]; «influencer marketing уже не просто тренд будущего, который способен потеснить традиционные способы продвижения... С помощью лидеров мнений - своего рода новых медиа - компании могут эффективно продвигать новые и существующие бренды, товары и услуги» [Емельянов, Макеева 2019: 521].

Мы не будем приводить еще примеры, чтобы не перегружать нашу работу, но в целом виден тренд на отождествление инфлюенсера и лидера мнения. Также можно отметить, что для отечественных исследователей инфлюенсер - это, прежде всего, феномен из области продвижения и продажи какихлибо товаров, т.е. инструмент, с помощью которого в современных условиях можно эффективно воздействовать на аудиторию с целью «заставить» купить какой-то продукт. На наш взгляд, ни уподобление инфлюенсера лидеру мнений, ни представление его как явления только из мира маркетинга не является обоснованным. Прежде всего рассмотрим проблему уравнивания в смыслах понятий «инфлюенсер» и «лидер мнений».

И в данном случае мы подходим к теории П. Лазарсфельда [Katz, Lazarsfeld 1955], который, собственно, и ввел термин «лидер мнения» для индивида, к чьему мнению прислушиваются люди, которые считают его авторитетом в определенном вопросе или вопросах, т.к. у него есть качества более выдающиеся, чем у этих людей. Лидеры мнения отличаются от своих последователей, членов так называемой референтной группы, «более развитым чувством эмпатии, широким использованием массмедиа, активностью в общественной жизни» [Бакулев 2005: 49] и другими качествами, которые ставят его выше остальных членов этой группы.

Причем необходимо отметить, что П. Лазарсфельд рассматривал прежде всего влияние лидеров мнения в процессе восприятия и передачи информации медиа. Этот исследователь пришел к выводу, что информация из медиа поступает к большинству реципиентов не напрямую, а пройдя через лидера мнения, 
и уже в его интерпретации. Первоначально П. Лазарсфельд назвал свою теорию «двухступенчатым потоком информации», т.к. считал, что информация из медиа сначала попадает к лидеру мнения (первая ступень), а потом, уже переработанная и интерпретированная им, она транслируется членам референтной группы (вторая ступень). В дальнейшем исследователь использовал термин «многоступенчатый поток информации, доработав теорию, но основная ее суть от этого не изменилась, просто П. Лазарсфельд обозначил возможность наличия более сложной системы лидеров мнения, где информация, как по ступенькам, спускается с более высокого уровня на более низкий.

Исходя из всего сказанного выше, можно сделать вывод, что отождествление инфлюенсеров и лидеров мнения не совсем корректно. Инфлюенсер - это более широкое понятие, чем лидер мнения, т.к. лидер мнения - это всегда всего лишь промежуточная ступень между медиа и потребителями информации, он не имеет самостоятельности, а может только анализировать, интерпретировать и передавать дальше информацию, получаемую из средств массовой коммуникации. Инфлюенсер же может быть как передаточным звеном, ретранслирующим чьи-то месседжи, так и самостоятельным создателем транслируемого контента.

В связи с этим нам представляется, что более корректным с социологической точки зрения будет отождествлять инфлюенсера с «медиазначимым другим» [Захаркин 2018], понятием, которое было введено в результате изучения влияния медиа на процессы вторичной социализации. В современном мире, где огромную роль играют медиа (и особенно новые медиа за счет активного развития Интернета), медийные личности, не имея непосредственной связи с получателями производимого ими контента, благодаря СМК входят в ближайшее смысловое окружение этих реципиентов и становятся для них значимыми другими, влияя на их жизненную позицию в разных областях. В информационном обществе значимые другие приобретают новые стороны существования. Во-первых, значимым другим для медиапотребителя становится совершенно посторонний для него человек не из непосредственного круга его общения, если этот индивид в медиасреде имеет соответствующий статус и воспринимается реципиентом как определенный эталон. Во-вторых, увеличивается число социализантов, на которых может влиять значимый другой. Если раньше он мог воздействовать только на индивидов, с которыми непосредственно общался, что накладывало определенные ограничения на их число, то в современных условиях развития медиа таких ограничений нет, и влияние может распространяться на массы, которые могут насчитывать тысячи или даже миллионы индивидов.

Поэтому можно предложить определение, что медиазначимый другой индивид, который оказывает социализирующее воздействие, используя медиаканалы. Медиазначимые другие - это фактор влияния на значительные сегменты общества, а не на группы людей, которые знакомы друг с другом, и влияние в которых происходит непосредственно. «Таким образом, виртуальный персонаж во многих аспектах начинает заменять индивидам, особенно детям, подросткам и молодым людям, традиционных значимых других: родителей, учителей, старших родственников и т.д. Происходит этот процесс вследствие объективных причин, т.к. медиазначимые другие стали намного актуальней для индивидов, чем их традиционные связи, а также медиазначимые другие могут быстрее и актуальнее интерпретировать и объяснять все происходящие в обществе изменения, а также давать полезные советы для успешного встраивания в общество в рамках этих изменений» [Захаркин 2018: 43]. 
Кардинальное отличие между значимым другим и медиазначимым другим, помимо каналов социализационного воздействия, лежит в основе социализационного влияния каждого феномена. Значимые другие влияют на социализанта за счет статуса, который выдается им автоматически. Влияние значимых других уже институционализировано в обществе, например в статусе индивида как учителя, преподавателя, близкого или дальнего родственника и т.д. Медиазначимый другой оказывает социализационное влияние на реципиентов в рамках отсутствия формализованных основ для такого воздействия, также у медиазначимых других коммуникация с аудиторией происходит не лично, а в опосредованных условиях с помощью медиа.

Такое воздействие, как нам кажется, достигается двумя факторами. Первый фактор - иррациональный. Он подразумевает, что медиазначимый другой в основе своей природы имеет высокий уровень привлекательности для индивида, воспринимающего его контент. Второй фактор - рациональный. Медиазначимые другие могут оказывать влияние на свою аудиторию, т.к. они являются авторитетами для тех, кто потребляет транслируемую ими информацию. Реципиенты считают, что медиазначимые другие обладают по сравнению с ними более выдающимися способностями, возможностями или знаниями, что и дает возможность медиазначимым другим влиять на таких индивидов. Можно предположить, что основа феномена влияния медиазначимых других заключается в слиянии эффектов иррационального и рационального направлений воздействия. Так происходит, когда индивид начинает получать контент медиазначимого другого, выбирая его, прежде всего, по внешним характеристикам или харизме, а затем уже на рациональном уровне принимая его как авторитет в определенной области. И обратная ситуация: сначала индивид воспринимает медиазначимого другого как источник актуальной, полезной или проверенной информации, а затем проникается к нему симпатией, и рациональный фактор уже перестает быть доминирующим. В итоге сила влияния медиазначимых других на свою аудиторию определяется тем, что иррациональный и рациональный аспекты воздействия сливаются в единый конструкт, который обеспечивает синергию воздействия.

Таким образом, инфлюенсеров более корректно синонимировать с медиазначимыми другими, а не с лидерами мнений. Инфлюенсер - это медиаперсона из области новых медиа, которая может оказывать воздействие, в т.ч. и социализирующее, на своих последователей, число которых может варьироваться от нескольких десятков до масс, насчитывающих миллионы человек. К нашему определению близко мнение, которое определяет инфлюенсера как человека, «обладающего большой лояльной аудиторией, которая доверяет его мнению и на которую он может оказывать то или иное влияние» [Кислицына 2019: 54].

Исходя из этого, вернемся к тезису отечественных исследователей, с которым мы не можем согласиться: инфлюенсер - это прежде всего феномен из области продвижения и продажи каких-либо товаров. Для этого изучим исследования отечественных и зарубежных авторов, которые относят возможности влияния инфлюенсеров на более широкий спектр элементов общественной системы.

Так, А.А. Кислицына считает, что инфлюенсеры играют огромную роль в политической сфере общества: «инфлюенсер, публикуя посты, твиты, видео, выходя в прямой эфир, транслируя свою позицию относительно того или иного события в политической жизни общества тысячам или миллионам подписчиков в социальных сетях, способен достигнуть большего охвата аудитории и стать эффективным инструментом продвижения в условиях современного информационного общества» [Кислицына 2019: 54]. Еще один важный момент 
воздействия на аудиторию - это формирование системы ценностей. Отметим такую концепцию: увидев и впечатлившись роскошной и сказочной жизнью инфлюенсеров напоказ, фолловеры могли подумать, что эта «виртуальная» жизнь является нормой, поверить, что «актерская» жизнь может быть подлинной/реальной, а затем изменить свое восприятие внешнего мира. Существуют определенные риски показа проплаченных фотографий нереальной, но невероятной жизни-мечты: в основном это касается молодых людей, которые могут чувствовать себя неполноценными, вплоть до депрессивных состояний, потому что они не могут жить такой жизнью сами [Leparoux, Minier, Anand 2019: 424].

Катаржина Гарвол по результатам своего исследования утверждает, что инфлюенсеры оказывают большое влияние на своих последователей как в вопросах, связанных с принятием решений (например, покупки), так и в мировоззренческих вопросах, подтверждая это цифрами своего исследования [Garwol 2020: 276]. Росио Паломек Ресио считает, что инфлюенсеры, с одной стороны, выступают в качестве товара (часто сами становятся брендом), с другой - формируют культурные установки своих последователей при условии, что имидж инфлюенсера становится достаточно сильным, чтобы влиять на поведение его последователей [Паломек Ресио 2020].

И закончим мнением Кристал Абидин и соавторов относительно возможности инфлюенсеров влиять на последователей не только в области продаж. В своей статье они отразили исследование, которое продемонстрировало, что во время эпидемии COVID-19 инфлюенсеры в Австралии, Китае, Японии и Южной Корее активно начали продвигать социально грамотное поведение, инициировав среди своих фолловеров тренд поощрения социального дистанцирования и надлежащей гигиены. В Китае местные репортеры заинтересовались группой проживающих за границей пожилых женщин, которые рассказали, как они использовали Instagram и YouTube, чтобы призвать людей соблюдать правила гигиены и прекратить дискриминацию и расизм. Австралийские и корейские инфлюенсеры также были замечены в продвижении практик социального дистанцирования, мытья рук, использования масок и ответственного этикета при кашле. В Австралии в приложении для коротких видео TikTok стали популярны танцы и мемы, сопровождающие мытье рук, а также вирусное распространение ретвитов в Твиттере, которые, по оценкам правительства, обошлись бы около 30 млн долл., если бы распространялись по рекламным каналам. В нескольких статьях отмечались инфлюенсеры, участвующие в официальных кампаниях с учреждениями здравоохранения и правительствами для оказания помощи в усилиях по восстановлению после COVID-19 [Abidin et al. 2021: 123].

Также инфлюенсеры в этих странах активно боролись с проявлениями расизма и ксенофобии, вызванными информацией о том, что коронавирус возник в Китае в результате употребления в пищу местными жителями экзотических животных. Как отмечают Абидин и соавторы, некоторые инфлюенсеры также называли негативные примеры социального поведения, например, расизм и ксенофобию по отношению к азиатам, панические покупки и накопление запасов. В частности, сообщалось, что инфлюенсеры азиатского и австралийского происхождения подвергались расистским и ксенофобным нападкам - от выражающих ненависть комментариев в их социальных сетях (например, «перестаньте есть летучих мышей») до неудобного общения на публике. В ответ некоторые из них стали выступать в качестве «послов обеих культур», привлекая внимание к такому поведению и создавая комментарии и контент для просвещения своих последователей [Abidin et al. 2021: 124]. 
Таким образом, мы видим, что влияние инфлюенсеров распространяется не только на область продаж. По нашему мнению, они могут влиять на практически любую область общественной жизни. Пространство социальных сетей позволяет интернет-пользователям комментировать и интерпретировать актуальные события. Социальные сети выступают в качестве основного источника информации, особенно для молодежи. Для инфлюенсера сейчас особенно важной является коммуникация с помощью сети Интернет. Конечно, можно сказать, что это не обязательная его составляющая, т.к. инфлюенсер может использовать любое медиа для коммуникации, но Интернет сейчас является наиболее эффективным СМК в современной реальности. Интернет - это та площадка, с помощью которой можно быстро донести сообщение и сразу получить обратную связь; коммуникация идет напрямую - от индивида к индивиду. В этом случае личности, прежде всего из новых медиа, могут входить в ближайшее окружение индивидов, становясь им ближе родственников, а индивиды, в свою очередь, как им кажется, включены в ближнее окружение инфлюенсера, ощущая свою избранность. Данный феномен уже охватывает тысячи и миллионы людей. Это позволяет нам сделать вывод, что инфлюенсеры приобретают значимый вес для своих последователей и способны оказывать заметное влияние во всех областях общественной жизни.

Анализ исследования ВЦИОМа «От блогеров - к инфлюенсерам: борьба за внимание и влияние на аудиторию. Новые тренды» ${ }^{1}$, проведенного в конце 2020 г., позволил выделить три интересные для нашего исследования идеи.

Во-первых, подтверждается наш тезис, что инфлюенсера нельзя отождествлять только со сферой какого-либо коммерческого продвижения: исследование ВЦИОМа показало, что, по мнению россиян, «фактически популярным блогерам приходится использовать две ролевые модели: первая - ньюсмейкер, носитель трендов, гражданской позиции; вторая - рыночный игрок в информационном пространстве» ${ }^{2}$. Таким образом, инфлюенсеры могут оказывать трансформирующее воздействие на многие социальные сферы, а не только способствовать продажам.

Во-вторых, респонденты отмечают персонализированность контента инфлюенсеров, который позволяет им устанавливать тесную связь со своими фолловерами и оказывать воздействие на них. «Продукт блогера намеренно персонализирован и как раз этим интересен аудитории» 3 .

И в-третьих, закономерность, которая довольно очевидна, но в нашей работе она еще не звучала: «ожидаемо, что основной аудиторией для блогеров выступает молодежь. Среди них наиболее высока доля читающих блоги и просматривающих видеозаписи блогеров (63\%). Причина этого не только в более высокой интернетизации молодых поколений - этот фактор постепенно выравнивается (73\% россиян пользуются Интернетом ежедневно, еще $12 \%$ не менее одного раза в месяц). В значительной мере поколенческие различия обусловлены массовым притоком самих блогеров из молодежной среды и приходом новых технологических платформ, которые также осваиваются новыми поколениями. Стилистика, язык, подбор тем многих блогеров настроены на близкую им среду» ${ }^{4}$.

\footnotetext{
1 От блогеров - к инфлюенсерам: борьба за внимание и влияние на аудиторию. Новые тренды. Опрос ВЦИОМа от 24 сентября 2020 г. Доступ: https://wciom.ru/analytical-reviews/ analiticheskii-obzor/ot-blogerov-k-inflyuenseram-borba-za-vnimanie-i-vliyanie-na-auditoriyunovye-trendy (проверено 27.11.2021).

2 Там же.
3 Там же.
4 Там же.
} 
Таким образом, реализуя свое собственное исследование, призванное прежде всего изучить влияние инфлюенсеров на аспекты жизни нашего общества, не связанные с продажами, мы будем ориентироваться на людей в возрасте от 18 до 45 лет, которые в исследовании ВЦИОМа показали самый высокий уровень ориентированности на инфлюенсеров. В исследовании использовался метод интервью. В начале 2021 г. были опрошены 72 чел., гендерное соотношение - $50 \%$ на $50 \%$. Был задан ряд вопросов, призванных выяснить влияние инфлюенсеров на аудиторию в сферах, не связанных с продажей чего-либо.

На вопрос: «Знаете ли Вы, кто такие инфлюенсеры?» - 58\% опрошенных ответили «да», и $42 \%$ ответили «нет». Таким образом, можно сделать вывод, что большая часть респондентов знакома с термином «инфлюенсер». При этом интересно, что в рамках возрастного диапазона 18-30 лет знакомо с этим термином подавляющее большинство - 75\%, в категории 31-40 лет - примерно $50 \%$ на 50\%, в возрасте от 41 до 45 лет - только $34 \%$ знают этот термин. Это еще раз подтверждает представленные выше данные ВЦИОМа о том, что значимым фактором погруженности в современные информационные тенденции является возраст аудитории.

На вопрос: «Есть ли такие личности в социальных сетях, которые оказывают на Вас влияние?» - $71 \%$ респондентов ответили положительно, что говорит о том, что, аудитория ощущает влияние контента социальных сетей. Интересно, что возрастная категория 41-45 лет опять же стала маркером возрастной дифференциации, т.к. только примерно $50 \%$ респондентов этого возраста признали влияние личностей из социальных сетей. Эта тенденция может быть показателем подсознательного отрицания такого воздействия среди людей старшего возраста, т.к. некоторые интервьюеры отмечали у таких респондентов принципиальное, а иногда и агрессивное нежелание признавать влияние контента социальных сетей.

Для того чтобы определить, в каких сферах, помимо продаж, респонденты фиксируют воздействие личностей из социальных сетей, был задан вопрос: «Назовите сферы, не связанные с продажами, в которых эти личности оказали на Вас воздействие или влияние». Было указано 20 вариантов ответов, приведем их здесь по мере уменьшения числа упоминаний: здоровье, политика, бьюти-индустрия (все, что связано с красотой), социальные проблемы, мода, психология, спорт, профессия, культура, путешествия, музыка, игровая индустрия, развлечения, образование, туризм, экология, кулинария, наука, живопись, книги. Таким образом, можно отметить, что влияние инфлюенсеров распространяется практически на весь спектр общественных сфер.

Отвечая на вопрос: «Назовите примеры такого воздействия или влияния», - респонденты чаще всего отмечали «изменения в политической позиции», «толчок к ведению здорового образа жизни, похудению и занятию спортом», «появление мотивации к саморазвитию», «осознание важности экологически правильного образа жизни», «изменения в мировоззрении», «изменения восприятия в отношениях мужчины и женщины». Остальные ответы были в единственном числе, из них можно выделить следующие наиболее интересные: «изменение отношения к сексуальным меньшинствам в положительную сторону», «показывают лайф-стайл, к которому стоит стремиться», «формирование представлений о ситуации в мире», «формирование отношения к митингам Навального», «подталкивание к отказу от прививок» и даже «подкачала губы».

Также в исследовании мы рассмотрели актуальную тему влияния инфлюенсеров на восприятие аудиторией проблемы коронавируса и ограничительных 
мер, связанных с его распространением. В теоретической части мы писали о том, что за рубежом некоторые инфлюенсеры активно включились в продвижение защитных мер, призванных остановить стремительное распространение вируса. Мы решили уточнить у респондентов, затрагивают ли инфлюенсеры эту тему, если да, то с какой позиции - сторонников запретительных мер или ковид-диссидентов, и прислушиваются ли респонденты к мнению инфлюенсеров по этой животрепещущей проблеме.

Прежде всего, необходимо отметить, что большинство респондентов отмечают довольно активное обсуждение данной проблемы в интернет-пространстве, т.к. на вопрос: «Замечали ли Вы, что личности, которые оказывают на Вас влияние, обсуждали ситуацию с пандемией коронавируса и ограничительными мерами?» - положительно ответили 68\% респондентов. При этом большинство инфлюенсеров признают опасность коронавируса: на вопрос: «В каком направлении они рассуждали: признавали опасность коронавируса и призывали к ограничительным мерам или не признавали его опасность и не поддерживали ограничительных мер?» - $82 \%$ ответивших отметили, что инфлюенсеры осознают опасность и призывают к ограничительным мерам.

Основными императивами инфлюенсеров, которые признавали опасность коронавируса, были: «необходимо быть осторожными», «необходимо соблюдать ограничительные меры», «это коснулось знакомых», «личный опыт», «необходимо соблюдать общественную безопасность». Аргументы, которые приводили инфлюенсеры, отрицающие опасность ковида: «этого не существует», «фейковые видео», «двойные стандарты», «ограничительные меры недейственны», «сгущают краски».

Можно отметить, что к мнению ковид-диссидентов прислушалось незначительное число респондентов ( $2 \%$ отвечавших), в основном принималось мнение инфлюенсеров, которые призывали к ограничительным мерам (43\%), или респонденты отмечали, что вообще не прислушивались к мнению инфлюенсеров (55\%). Респонденты отметили, что если они не прислушивались к мнению инфлюенсеров, то прежде всего ориентировались на позицию врачей как специалистов, а не медийных персон (21\%), друзей (20\%), родных (12\%), государства (Минздрав) (7\%), девушки/мужа (7\%) и т.д. Отдельно стоит отметить, что значительное число респондентов (33\%) отстаивали позицию, что сформировали свою точку зрения сами, без каких-либо внешних факторов воздействия.

В результате исследования можно сделать вывод, что гипотеза о влиянии инфлюенсеров на мнение своих фолловеров в областях, не связанных с продажами, подтвердилась. Как медиазначимые другие инфлюенсеры могут оказывать социализирующее влияние в рамках разнообразных сфер, с которыми взаимодействуют современные индивиды. В части влияния инфлюенсеров на восприятие респондентами опасности коронавируса можно отметить, что значительная часть ответивших прислушалась к мнению медиазначимых других, но также огромное влияние до сих пор оказывают традиционные значимые другие, т.е. ближайшее окружение отвечавших.

В заключение можно констатировать, что инфлюенсеры начинают оказывать все большее социализирующее воздействие на современное общество. И, как показало даже наше исследование, чем младше индивидуум, тем большее воздействие оказывают инфлюенсеры, чем он старше, тем слабее влияние. В дальнейшем можно прогнозировать все большее воздействие инфлюенсеров: по мере того как современная молодежь будет взрослеть, ей на смену будут приходить поколения, еще более подверженные процессам влияния новых медиа. 


\section{Список литературы}

Бакулев Г.П. 2005. Массовая коммуникация: западные теории и концепции. М.: Аспект Пресс. 176 с.

Вицелярова К.Н., Опря А.А., Балякно А.А. 2020. К вопросу об инфлюенсерах как основного аспекта повышения продаж продвигаемого продукта в Social media. - Естественно-гуманитарные исследования. № 29(3). С. 114-116.

Емельянов Н.В., Макеева Т.В. 2019. Перспективы развития influencer marketing: тренды и проблемы применения в России. - Синергия наук. № 31. C. 515-522.

Захаркин Р.А. 2018. Роль значимых других и медиа значимых других в процессе вторичной социализации. - Общество: социология, психология, педагогика. № 2. С. 41-44.

Кислицына А.А. 2019. Маркетинг влияния в современных политических кампаниях. - Общество: политика, экономика, право. № 8(73). С. 54-58.

Куприянова Д.А. 2019. Инфлюенсеры и их возможное влияние на продвижение туристских дестинаций Российской Федерации. - Сила систем. № 2(11). C. 22-24.

Никитина Л.С. 2018. Инфлюенсеры и лидеры мнений как эффективные инструменты современного интернет-маркетинга. - Аллея науки: научнопрактический электронный журнал. № 9(25). С. 508-511.

Abidin C., Lee J., Barbetta T., Miao W. 2021. Influencers and COVID-19: Reviewing Key Issues in Press Coverage across Australia, China, Japan, and South Korea. Media International Australia. Vol. 178. No. 1. P. 114-135.

Garwol K. 2020. Influencers - Contemporary Authorities of the Young Generation?

- European Journal of Sustainable Development. Vol. 9. No. 4. P. 273-280.

Katz E., Lazarsfeld P. 1955. Personal Influence: The Part Played by People in the Flow of Communications. Glencoe, Ill.: The Free Press. Xx+400 p.

Leparoux M., Minier P., Anand A. 2019. The Online Influencers Strategies and Their Impact on Consumers Decisions Process. - Вестник СПбГУ. Сер. Менеджмент. T. 18. Вып. 3. С. 419-447.

Monge Benito S., Elorriaga Illera A., Olabarri Fernández E. 2020. YouTube Celebrity Endorsement: Audience Evaluation of Source Attributes and Response to Sponsored Content: A case study of influencer Verdeliss. - Communication \& Society. Vol. 33. No. 3. P. 149-166.

Palomeque Recio R. 2020. Postfeminist Performance of Domesticity and Motherhood during the COVID-19 Global Lockdown: the case of Chiara Ferragni. Feminist Media Studies. 12 Oct.

Schouten A., Janssen L., Verspaget M. 2019. Celebrity vs Influencer Endorsements in Advertising: the Role of Identification, Credibility, and Product-Endorser Fit. International Journal of Advertising. Vol. 39. No. 2. P. 1-24. 
ZAKHARKIN Roman Aleksandrovich, Cand.Sci. (Soc.). Associate Professor at the Department of Communications and Media, School of Arts and Humanities, Far Eastern Federal University (10 Ajax Bay, Russky Island, Vladivostok, Russia, 690922;rom_zah@mail.ru,zakharkin.ra@dvfu.ru)

ARGYLOV Nikita Antonovich, Cand.Sci (Pol.Sci.), Research Fellow at the Department of Communications and Media, School of Arts and Humanities, Far Eastern Federal University (10 Ajax Bay, Russky Island, Vladivostok, Russia, 690922;

argylov.na@dvfu.ru)

\title{
INFLUENCERS AS MEDIA SIGNIFICANT OTHERS: MODERN TRENDS OF SECONDARY SOCIALIZATION
}

\begin{abstract}
The article investigates the phenomenon of influencers from a sociological point of view. This concept of great current interest was defined in the article on the base of multiple sources. The study integrates the main concepts of literature on social media influencers, secondary research data and the results of interview conducted by the authors. The authors give a comparison between different approaches with highlighting common features of influencers. They emphasize the trend of domestic scholars to identify an influencer and an opinion leader, as well as to refer influencers to the promotion of goods and services only. This study proposes consideration of Lazarsfeld's two-step communication flow theory as an alternative view regarding the foregoing approach to influencers and opinion leaders (the term initially set by Lazarsfeld in the framework of above indicated theory). Therefore, the paper proposes to use a more correct term «media significant other» which is explored in this article together with interrelation to the term «influencer». The authors also question the idea that influencers can have an impact in the field of sales only. The hypothesis of comprehensive nature of influence has been confirmed by the results of a sociological interview: 72 people were interviewed, and the results of the research demonstrate that the social impact of influencers is increasing and extending to various spheres of public life. The impact of the COVID issue on social network communications is also discussed. The authors conclude that the degree of exposure to influencers depends on the age of an individual and concerns almost all spheres of life.
\end{abstract}

Keywords: influencer, media significant other, opinion leader, P. Lazarsfeld, coronavirus, COVID-19 